\title{
EL AMONTONAMIENTO: UNA CONDICIÓN DE ADICIÓN
}

\author{
PILING UP: AN ADDITION STATE
}

\section{BECQUER ADONIS REYES SOLIS ${ }^{1}$}

Recibido: 15 de mayo de 2017

Aceptado: 29 de agosto de 2017

\footnotetext{
${ }^{1}$ Universidad Politécnica Salesiana, Sede Quito, El Girón, Carrera de Psicología, Quito, Ecuador (breyes@ups.edu.ec).
} 



\title{
EL AMONTONAMIENTO: UNA CONDICIÓN DE ADICIÓN
}

\section{PILING UP: AN ADDITION STATE}

\author{
Becquer Adonis Reyes Solis
}

Palabras Clave: amontonamiento, adición, duelo, dolor psíquico, objeto, abyección, repetición, psicoanálisis.

Key Words: Piling up, Addition, Mourning, Psychic suffering, object, abjection, repeating, psychoanalysis.

\section{RESUMEN}

La humanidad siempre ha tenido que enfrentarse con lo real; sin embargo, en cada época, en cada cultura, los intentos fracasados de tolerar y de-velar, se dan en el nivel de lo cotidiano. En el espacio de encuentro con el otro podemos evidenciar una serie de fenómenos que dan cuenta de nuestra subjetividad. Pero, hay, un fenómeno en particular que llama nuestra atención, es esta forma singular de ignorar al otro en nuestro encuentro con él.

Es el lugar, la posición, que se le da al objeto, lo que evidencia el su- frimiento que le produce al sujeto enfrentar la falta. La adición como amontonamiento, fracasa inminentemente en este intento de no querer saber del Otro. Se trata de no renunciar al objeto, que se mantenga ahí, que se mantenga ahí sin estar. En un lugar de espera, como una reserva de la que no echamos mano. Por lo que, queda en el lugar de lo absurdo. Es un lugar de no-acción desde el que evitamos la penosa tarea de dar cabida al dolor psíquico.

Es el lugar de la irresponsabilidad, de la "incapacidad" de hacernos cargo de 
nuestras producciones. Donde el otro, desde el lugar del enemigo, es el mejor depositario de la imposibilidad de enfrentarse a la falta.

\section{ABSTRACT}

Humanity has always had to face with "The Real". Though in each time and culture the failed attempts to tolerate or veil are shown in everyday life. Within the encounter with the fellow men, a series of phenomena that show our subjectivity can be found. Never the less, a particular one calls our attention, that is, a way of ignoring the fellow men as we seek our encounter with them.

It is the place and the position the subject gives the object what reveals all the suffering produced on the subject to face the basic fault. "Addition" as an action of piling up immanently fails on its attempt on not wanting to know about The Other. This is related to not abandoning the object, keeping it close, being there without being. It stays in a sort of waiting state, as a reserve that we don't use. That is why this position gets stuck in the absurd. It is a place of non-action from which we avoid giving a chance to the painful task of psychic suffering. It is the place of irresponsibility, incapacity of taking charge of our productions, where the fellow men, placed as the enemy, are the ones where we put our own impossibility of facing the "lack" or basic fault.

\section{INTRODUCCIÓN}

"La ceguera emocional es un lujo que sale caro y que la mayoría de las veces es (auto) destructivo"

Miller. 2005:10

Hay algo que no aceptamos y que se manifiesta en la cotidianidad como fenómenos irrelevantes, pero, que dan cuenta de un proceso de subjetividad. Básicamente es una condición de la forma de vincularse con el otro, ignorándolo.
Las formas en las que el malestar se oferta en nuestra cultura mantienen las distorsiones que su historia le ha permitido dejar de lado. La sociedad ecuatoriana, en sus múltiples renuncias, no ha dejado de constituir en su vida cotidiana una for- 
ma de vérselas con aquello que insiste y que continuamente muestra ocultándose.

En este espacio, el amontonamiento, nos sorprende confrontándonos a lo real. Enfrentados en nuestra condición humana con aquello del orden de lo insignificante buscamos ese orden de la novedad como una escasa forma de no renuncia al goce.

Nuestra propuesta parte de considerar la relación que se da entre la subjetividad y el fenómeno de amontonamiento como resultado de la condición de adición.

El malestar en la historia humana ha dado muestras de crueldades evidentes, fosas comunes, cadáveres publicados en diarios, guerras informáticas, desastres nucleares. Muestras de la capacidad de eliminación de un otro, elegido como enemigo depositando sobre él lo intolerable. El malestar no se muestra solamente en los grandes íconos de la destrucción humana, también en las expre- siones superfluas de la cotidianidad. Ya Freud en El Malestar de la Cultura (1930) y en Psicopatología de la vida cotidiana (1901), expresa la valoración sobre aquellos fenómenos que definen lo humano: la condición de lo absurdo. Aquello que aparece y sorprende, ese inconsciente pulsátil, que no deja de sorprendernos y de generarnos, en el acontecer cotidiano, un padecer. El lugar que se le da al objeto, la posición.

El amontonamiento evidencia el sufrimiento que al sujeto le produce el afrontar su condición de pérdida. En el espacio de lo imaginario suponemos a la acumulación "adición" de elementos residuales como una forma de ignorar la falta, esa inscripción de la falta de objeto, de la que no queremos saber porque es la muestra de un Otro. Cada quien intenta superar el estado de renuncia a la satisfacción. El fracaso es inminente, y el sufrimiento se manifiesta, presentificando la incapacidad de negar la falta.

\section{DE NUESTRO FENÓMENO}

La acción de adición implica la añadidura, definida como el acrecentar un elemento u objeto. La adición en su condición verbal se define como añadir algo a una cosa (RAE), y añadir como agregar, incorporar algo a otra cosa; aumentar, acrecentar, ampliar (RAE).
Con estas definiciones partimos para considerar un vocablo muy utilizado en nuestra sociedad que se ha considerado como equívoco por la redundancia que propone: "más mejor"; que resulta, en la condición popular del uso, una expresión de un superlativo donde 
"mejor" expresa la característica exagerada del "más". Consideremos otra posibilidad: la elipsis verbal; es decir, que si le ubicamos un verbo en el medio de los vocablos obtenemos una condición de pensamiento que se expresaría en un "más es mejor" que condiciona la idea de adjudicar la cantidad como valiosa en el medio de la sociedad ecuatoriana.

El valor a la cantidad expresada se da en condiciones de vida cotidiana donde, por ejemplo, en algunos espacios se cree que la comida es buena con el añadido de que sea bastante. La abundancia es premiada por la cultura y se expresa en múltiples espacios simbólicos del lenguaje o en el simple decir.

Pero tenemos que en nuestra frase propuesta de forma hipotética "más es mejor" se sustrae el verbo; es decir, la condición de la acción. Por lo que se deja sin acción, el añadido, sin el actuar.

Proponemos otros fenómenos que nos llevarían a dar cuenta de esa inacción presente en la sociedad ecuatoriana que a la vez que evidencia esconde, muestra y devela en tanto permite la no-acción y el detenimiento de un proceso subjetivo. Podemos decir que el fenómeno del amontonamiento nos muestra adición.

Además, las consideraciones generales sobre el uso de los espacios determinan modalidades del uso y de la ubicación que un objeto establece respecto a otro, por lo que si se ubican varios elementos en un determinado espacio, sin establecer un orden o un principio que los regulen, entonces hablamos de amontonar.

Así la RAE define amontonar como "1. Poner unas cosas sobre otras sin orden ni concierto, 2. Juntar, reunir, allegar cosas en abundancia, y 3. Juntar y mezclar de manera confusa y desordenada" (RAE). Proveniente del término montón, usado como condición de abundancia y de exageración, mantiene la atención sobre las personas en las que se las considera poco útiles y además con una virtuosidad de vulgaridad en expresiones como "ser del montón".

Con regularidad nos encontramos frente a fenómenos que establecen las condiciones mencionadas, por ejemplo: en el ejercicio diario de tomar transporte público; en las disposiciones dentro de las casas observamos elementos como los recuerdos (de bautizos, matrimonios) de eventos que ya no se recuerda la pertenencia; en las denominadas bodegas donde se guardan elementos como tuercas y tornillos, entre otros. En mochilas y bolsos de mano la existencia de objetos bizarros; la lista sería mucho más extensa y por lo tanto recortamos en este espacio ya que nos interesa ir hacia el fenómeno de vida. Nos basta con definir que son elementos que están ahí sin utilidad aparente. 
Cuando personas se acercan a las consultas psicológicas, como, por ejemplo, el planteamiento de no poder retirarse de una ruptura amorosa, suele establecerse como una condición de aferrarse a la situación, no siendo la persona a quien se extraña sino las condiciones que esta ofertaba como es la compañía. También suele darse una especie de coleccionismo de las anteriores relaciones bajo la queja de "jpor qué no nos podemos llevar bien!", "ipor qué no podemos conversar!" entre otros muchos decires. Si bien más adelante se lo consideraría como proceso de duelo, lo consideramos como un amontonamiento de las parejas, pues se mantienen en un espacio de la subjetividad. Diremos que se trata de mantener el objeto, de no renunciar y que se mantenga ahí sin estar.

Afirmar que se trata de un miedo a perder sería un tanto apresurado ya que el miedo a la pérdida estaría ligado a un fenómeno de inhibición. Pero nos interesa ir un tanto más allá.

De entre las dimensiones, consideremos el elemento del espacio y la repetición que se establece en una ubicación del objeto en una dimensión (lugar) de las posibilidades que se pueden o se pudieron dar. Aparece un constructo de la fantasía donde la insatisfacción produce un mundo diferente en una realidad otra, un mundo alucinado sin la circula- ción metafórica de los elementos-objeto. Efectivamente nos salta la incapacidad de la renuncia a la posesión del objeto, o en mayor detalle sería la incapacidad de la renuncia a las posibilidades que el objeto nos determina en la existencia del mismo, lo que pudo ser.

Se establece entonces la colección del objeto no en una secuencia de orden lógico o cronológico, sino en un montón donde se pierde entre los múltiples objetos pero se lo mantiene con la expectativa de que allí está para echar mano del mismo.

Podemos pensar, en un punto elemental, a la compulsión de repetición como una exigencia constante de trabajo, que se inscribe en el aparato psíquico bajo la forma de surcos donde se establecen las vías posteriores de recorridos libidinales en el infante. Así, Freud en Recordar, repetir, reelaborar, de 1914, considera a la compulsión de repetición en una vertiente clínica, en ese texto aborda el problema del olvido (como un bloqueo de impresiones, escenas y vivencias) opuesto al recordar y suma un factor: "que se «recuerde» algo que nunca pudo ser «olvidado» porque en ningún tiempo se lo advirtió, nunca fue conciente" (Freud, 1914:151). Como consecuencia, habría algo del inconsciente que exigiría ser recordado: una marca en el aparato anímico que no pertenece al sistema de representaciones conscien- 
tes pero que no se hallaría deslindada del principio del placer. En la clínica, sostiene Freud, se daría un evento muy frecuente, "el analizado no recuerda, [...] nada de lo olvidado y reprimido, sino que lo actúa. No lo reproduce como recuerdo, sino como acción; lo repite, sin saber [... .] que lo hace" (Freud, 1914:152). Por lo cual existe algo que no pasa al sistema de representaciones (al recuerdo) y se instala de otra forma en el aparato anímico; habría entonces, una especie de tramitación motriz del impulso.

La compulsión de repetición se relaciona con la transferencia pues "es sólo una pieza de repetición, y la repetición es la transferencia del pasado olvidado" (Freud, 1914:152); la compulsión de repetición se presenta siendo aquello "que sustituye ahora al impulso de recordar" como una forma de hacer presente y actual aquello perteneciente a un momento anterior (habría una actualización permanente del pasado en la trasferencia). Freud considera que "mientras mayor sea esta, tanto más será sustituida el recordar por el actuar (repetir)" (Freud, 1914:153); frente a mociones hostiles o hiperintensas existiría una necesidad de mayor represión con lo cual "el recordar deja sitio enseguida al actuar" (Freud, 1914:153).

Y Freud se pregunta ¿qué es aquello que se repite?, dando como secuencia: "el analizado repite en vez de recordar, y repite bajo las condiciones de la resistencia. [...] Repite todo cuanto desde las fuentes de su reprimido ya se ha abierto paso hasta su ser manifiesto" (Freud, 1914:153). Lo fundamental de esta repetición es que se encuentra dentro del campo del principio del placer.

En 1920, en Más allá del principio del placer, Freud retoma el problema de la compulsión de repetición, de forma distinta, en este escrito piensa a la compulsión de repetición como aquello que se encuentra en otro lugar que el reino del principio del placer. En este texto el autor analiza dos fenómenos principalmente: las neurosis de guerra y el juego infantil (en tanto fenómenos que se repiten a pesar del malestar que pudo haber generado la vivencia recordada) así el aparato busca "recuperar el dominio sobre el estímulo por medio de un desarrollo de angustia cuya omisión causó la neurosis traumática" (Freud, 1920); esta función busca restablecer en el aparato anímico el dominio del principio del placer que de alguna manera ha quedado abolido por el trauma: "excitaciones externas que perforan la protección antiestímulo" provocando en el aparato la abolición del principio del placer (dejando perforado al aparato). El aparato por su parte tendería de alguna manera a restablecer o intentar el restablecimiento del reinado del principio del placer para su funcionamiento, y lo hace intentando 
ligar la energía libre, es decir movilizando su energía hacia donde fue perforado el aparato (contrainvestidura).

La compulsión de la repetición quedaría por fuera del reino del principio del placer, es decir, estaría del lado de lo pulsional: aquello inconsciente que tiende a ser reproducido de alguna manera más allá del principio del placer -lo traumático-; Freud ubica este proceso como una resistencia del Ello, en tanto es un retorno de lo reprimido en el sentido en que busca la satisfacción pulsional por otro mecanismo que no sea el principio del placer.

La compulsión de repetición al no encontrarse en el reino del principio del placer, y al no tratarse de vivencias reprimidas (como nos fue propuesto en el texto de 1914) estaría previa al mecanismo de la represión, tratándose de una defensa primaria, una cualidad de la pulsión, en tanto búsqueda de un estado anterior y de su satisfacción por la vía más corta. Al ser destronado el principio del placer, la compulsión de repetición sería más originaria, más elemental y más pulsional. Tendería a buscar siempre el retorno.

Para resumir la postura freudiana sobre el tema citaremos la referencia dada en Inhibición, síntoma y angustia de 1926, donde dice:

Cuando el yo consigue defenderse de una moción pulsional peligrosa,
[...], sin duda inhibe y daña esta parte del ello, pero simultáneamente le concede una porción de independencia y renuncia a una porción de su propia soberanía. [...] Ahora lo reprimido está «proscrito», excluido de la gran organización del yo, sólo sometido a las leyes que gobiernan el reino de lo inconsciente.

En este párrafo se estaría hablando de la formación de la defensa primaria del yo, mediante la cual el yo adquiere la posibilidad de domeñar aquellas mociones pulsionales, pero además, pierde parte de sí en su lucha y los efectos posteriores son evidenciados en la compulsión de repetición. Pero Freud continúa diciendo:

Pero las consecuencias de la limitación del yo se vuelven manifiestas si luego la situación de peligro se altera de suerte que el yo ya no tiene motivo alguno para defenderse de una moción pulsional nueva, análoga a la reprimida. El nuevo decurso pulsional se consuma bajo el influjo del automatismo -preferiría decir de la compulsión de repetición-; recorre el mismo camino que el decurso pulsional reprimido anteriormente, como si todavía persistiera la situación de peligro ya superada. Por lo tanto, el factor fijador a la represión es la compulsión de repetición del ello inconsciente, que en el caso normal sólo es cancelada por la función libremente móvil del yo (Freud, 1926:144). 


\section{DEL OBJETO}

Ante los elementos ubicados en nuestro fenómeno, nos toma por asalto cuestionar cuál es su dimensión, ¿podemos definirlos a simple vista como un objeto? En las circunstancialidad de dichos elementos podríamos considerarlos como bizarros y articularles como elementos beta desde la apreciación de Wilfred Bion (1977). Entonces el estatuto del objeto llama nuestra atención.

En las consideraciones de S. Freud (1905) aparece el objeto en su dimensión ligada a la pulsión, en Tres ensayos de teoría sexual, en la condición de objeto de satisfacción, objeto que determina la repetición de la búsqueda como lo menciona en el Proyecto (1950) a partir de la vivencia de satisfacción. La falta aparece como condición de la humanidad y en cuyo caso el objeto es la evidencia de la falta, es objeto en tanto ausencia de objeto, deja su inscripción.

Es "una continuación de una tendencia donde se trata de un objeto perdido, de un objeto que se trata de reencontrar" (Menassa. 1996: 22)

La dimensión de la falta caracteriza al objeto, y Lacan ubica en el Seminario 4 (1956-1957) una diferencia:

Entre frustración de amory frustración del goce para mostrarnos que es diferente un objeto como don, que el objeto siempre inaccesible del goce, ya que el don está en el campo del amor y el objeto en el campo del goce [...] el objeto del goce, objeto siempre inaccesible. Objeto que se trata siempre de reencontrar, pues aunque se encuentre las coordenadas del placer no se encuentra el objeto, pues lo que se trata de encontrar es siempre el Otro absoluto del sujeto (Menassa. 1996: 22).

Mantenemos la condición de al menos dos objetos, uno que circula desde el orden del don y otro que es ubicado en la satisfacción en el campo del goce. Nos interesa tomarlo en su dimensión de objeto producido, de donde el objeto responde al proceso de alucinación descrito por Freud (1900) en la Interpretación de los sueños. Así Lacan en el Seminario 4 (1956-1957) propone a "el objeto alucinado sobre un fondo de angustia".

Lo cual nos lleva a proponer algunos elementos de nuestro fenómeno como un intento de velar aquella angustia frente a la falta, es decir, frente a la emergencia de lo real.

El camino nos conduce a la propuesta de la fobia, en cuyo movimiento J. Kristeva (2013) enlaza el miedo con el objeto y define el "objeto-ornato de la 
angustia" con el cual el objeto se define como una defensa contra la angustia.

Las formulaciones respecto de la fobia muestran el camino por donde el objeto resuelve la angustia frente a la falta y de donde su emergencia se postula como una formación como lo menciona Lacan en el Seminario 4 "instrumento para disfrazar, para enmascarar el fondo fundamental de la angustia" (195-1957) en una reacción que Freud había ubicado respecto de la fobia como una defensa frente a la pérdida de objeto.

Si bien el fenómeno que nos ocupa en este apartado no se trata de una variante de la fobia, hay que diferenciarlo ya que no se ubica el afecto de la angustia en sí mismo. El movimiento de angustia se encuentra petrificado y no aparece en los objetos propuestos.

Sin embargo, aparece una huella del registro de su procedencia: el miedo. Se propone una ilusión que deja lugar al miedo a la pérdida aunque al dejarla de lado solamente se expresa como una inhibición del miedo. Sobre este asunto Kristeva dice "el miedo, en un primer sentido, podría ser una ruptura del equilibrio biopulsional. Entonces, la constitución de la relación de objeto sería una reiteración del miedo, alternada por equilibrios óptimos pero precarios. Miedo y objeto marchan juntos hasta que uno reprime al otro." (Kristeva. 2013: 49) y concluye cuestionando "¿quién de nosotros lo lo- gra totalmente?" (Kristeva. 2013: 49).

Si bien el objeto es una alucinación, la fobia es un fracaso y una metáfora dice Kristeva y más que eso es una "alucinación de nada":

Ya que a los movimientos de condensación y desplazamiento que presiden su formación, se agrega una dimensión pulsional de valor anafórica, de indexación, que remite a otra cosa, a la no-cosa, a lo incognoscible. (Kristeva. 2013: 60)

En la posibilidad de petrificación de los elementos de fenómeno que hemos denominado amontonamiento se da nuestro fenómeno como la posibilidad de añadir a un lugar y dejarlo en él. Sin miramientos, sin pasiones, simplemente está ahí en la espera como una reserva para ser usado en un momento de reaparición. El momento esperado nunca llega, pero el objeto no se desecha ni produce síntomas, queda en un lugar del sinsentido, del absurdo de la vida.

Hacemos un paréntesis para ubicar Al síntoma definido del lado del psicoanálisis como aquella formación de compromiso. El conflicto lo visualizamos en este espacio como el fundamento de la vida. Freud siempre ubicó la dinámica psíquica como un conflicto: en la primera tópica nos encontramos con oponentes de conciencia versus 
inconsciente en primera instancia, de las dualidades pulsionales, principio de realidad versus principio de placer; en la segunda tópica el psiquismo es presentado bajo otra dinámica, yo -ello- super yo, y se incluyen a las antes mencionadas. Pensando en espacios diferentes, las instancias psíquicas generan una armonía en conflicto que se la denominó síntoma como la producción de la subjetividad frente al conflicto.

La experiencia psicoanalítica como el recurso para la producción de un posicionamiento lo remarca en su proceso como el tomar posición frente al síntoma sin la pretensión de su eliminación ya que el conflicto es lo que moviliza la producción del sujeto apuntalado en un organismo viviente. Si la producción del síntoma es la evidencia de la vida por ser su motor, eliminar es una contraposición a la vida, o mejor dicho un imposible y vano intento que solamente produce un silenciamiento del sujeto en términos de dominación y control social.

Al afirmar que no produce síntomas consideramos que el amontonamiento deja ahí. Es decir, que el amontonamiento no es un fenómeno sintomático en sentido psicoanalítico sino una inhibición. Lo cual no excluye las condiciones para generar otros factores de una forma estética exterior, como tendríamos el caso en la arquitectura de la ciudad donde las personas construyen sus casas con espacios sin sentido, vacíos y nunca los desechan; la expresión estética corporal, su comida es amontonar como se muestra el chaulafán popular. El amontonar genera formas expresivas en el mundo, eso guardado sin sentido produce formas de poner las cosas en su lugar. El orden de la casa es el orden psíquico del amontonar, no hay diferencia, porque es una sola dinámica.

Retornando a ese absurdo de la vida lo definimos como activo, se ejecuta en las formas de mostrarse de la persona, en la forma de relacionarse con el semejante. Un forma de entender es las denominadas interrelaciones de pareja en donde nunca se termina, todo queda guardado, las exparejas están ahí, pendientes, en un no lugar que se puede activar fácil. No se puede terminar la relación: se quedan ahí.

No se trataría de una cadena secuencial y metafórica, de una repetición o de un elemento en lugar de otro, sino es una indexación: el uno a lado del otro, como dos objetos que se juntan para intentar compartir su soledad y en el desencuentro se establecen como dos soledades habitando un espacio.

Del lado de la abyección aparece un espacio de ambigüedad que no es tolerada en nuestra época porque preferimos definir, delimitar y hacer nuestro montón, es parte del dejar de lado: es la muestra de la intolerancia a la renuncia. 
Kristeva define lo abyecto: es algo rechazado del que uno no se separa, del que uno no se protege de la misma manera que de un objeto. Extrañeza imaginaria y amenaza real, nos llama y termina por sumergirnos (Kristeva. 2013: 60).

La extimidad' aparece en este campo y no hay que resolverla, hay que tolerarla. Pero la abyección se nos plantea como:

Aquí la barra constituyente sujeto/ objeto se transforma en una gruesa e infranqueable muralla. Un yo (moi) herido hasta la anulación, trabado e intocable, se agazapa en alguna parte, en ninguna parte, sin más lugar que un lugar inhallable. Delega, por el lado del objeto, fantasmas, aparecidos, "falsos hermanos": un flujo de falsos yo (moi) y por eso mismo falsos objetos, simulacros de yo (moi) que afrontan objetos indeseables. Existe la separación, también el lenguaje, y a veces brillantemente, con realizaciones intelectuales aparentemente notables. Pero la corriente no pasa: es el clivaje puro y simple, el abismo sin traslación posible entre dos bordes. Ni sujeto ni objeto: petrificación por un lado, falsedad por el otro (Kristeva. 2013: 66)

El amontonamiento en la secuencia de los cadáveres de las representaciones de lo que se ha perdido produce la insoportable ruptura del vínculo con el otro. El efecto del amurallamiento y el borde de un "ni sujeto ni objeto" plantean la condición de falsedad que muestra en el plano imaginario una dimensión del disfraz, una veladura en la negación de la inexistencia del objeto.

Y culmina Kristeva su texto afirmando que nuestra época se mantiene en una no confrontación con lo abyecto. Diríamos, es preferible no-hacer en un montón.

\footnotetext{
${ }^{1}$ La consideración que aparece en el constructo de la extimidad Lacan la refiere en el seminario 16 para ubicar el elemento que se encuentra en nuestro lugar más íntimo y propio y sin embargo esta fuera y es externo. Se rompe con las dimensiones de ubicación dentro-fuera en la construcción subjetiva, ese sujeto engendrado en otro por la condición deseante pero que en su más íntima condición es extraño-externo. Para Graciela Brodsky (2012) propone a partir de la lectura de J. Miller que "Extimidad, el curso de Miller, es en el fondo un curso sobre la transferencia, sobre su resorte, sobre los recursos que inventa un sujeto para arreglárselas con ese objeto a que una vez extraído de su cuerpo puebla su mundo, alimenta sus fantasmas, su síntomas, sus sublimaciones, ese objeto que se mantiene a raya en la inhibición, que irrumpe en la angustia, pero, más radicalmente, que le permite olvidar que el Otro no existe, ya que con el objeto lo alimenta, lo ama, sufre por él, se enlaza con él. En síntesis, lo hace existir."

cfr. Miller. Extimidad. 2010
} 


\section{LA SEPARACIÓN: DUELO Y EL DOLOR}

Las condiciones de la posibilidad de retirarse establece también, la posibilidad de perder algo. Nos llevaría al movimiento que se establece en el duelo. Sin embargo, preferimos tomarlo dando un rodeo ya que la condición de reunir, Lacan, establece en el Seminario 11 (1964) como la lógica de la alienación y la aparición del objeto en la dimensión de la separación.

La renuncia a un objeto, esa posibilidad de establecer una distancia con el objeto condiciona un proceso que nos interesa ya que el fenómeno que nos excusa aquí se trataría de una imposibilidad de perder como consecuencia de producir una alternativa a la no producción de dolor psíquico.

Freud (año) en Duelo y melancolía considera que es un proceso debido a la pérdida del objeto. Se produce un trabajo de duelo que consiste en el retraimiento de la libido y la consecuente retirada de las investiduras sobre el objeto.

El procedimiento del duelo acarrea consigo la condición del dolor psíquico, que ya sería el establecimiento de un modo de defenderse, así J. Nassio (2007) manifiesta que:

Sabemos que el estado de dolor extremo por el que pasa la persona en duelo, esa mezcla de vaciamiento del yo y de tetanización de un recuerdo, es la expresión de una defensa, de un sobresalto de la vida (Nassio, 2007: 14)

Y define al dolor psíquico como "el afecto último, la última crispación de un yo desesperado que se contrae para no hundirse en la nada" (Nassio, 2007: 15)

La situación que permite el paso por un proceso de duelo se remite a la sustracción de un objeto ya sea de orden de la pérdida, del abandono o de la humillación. Se exige no el reemplazo o la acumulación de objetos, sino la imposibilidad de remplazarlo para permitir su circulación.

El amontonamiento plantearía una mortificación constante ya que suma cadáveres que no permiten la circulación, sino al contrario, exponen la condición estática, pero evita el dolor aunque no la angustia.

El dolor para Nassio consistiría en una prueba "la prueba de una separación irreversible [...] nos trastorna y nos obliga a reconstruirnos" (Nassio, 2007: 22). Y en tal condición se manifiesta como un límite en tanto afecto en un amurallado frente a la locura o la muerte.

En definitiva, el dolor en su forma defensiva es la presentificación de la defensa del yo ante el trauma y se da una sobreinvestidura que recae en la representación de lo perdido. 
Para Nassio el trabajo de duelo da inicio con el dolor psíquico, por lo que:

Hacer un duelo significa aprender a vivir con la ausencia [...] hacer duelo es aprender a amar de otro modo a la persona desaparecida, a amarla sin el estímulo de su presencia viva (Nassio, 2007: 81).

Las rupturas son posibles por la ausencia dada y el dolor un efecto-afecto por lo tanto el dolor es el afecto que expresa, en la consciencia, la percepción que tiene el yo -percepción hacia adentro- del estado de conmoción pulsional (trauma) provocado por la efracción no ya del envoltorio corporal del yo -como sucede en el dolor físico- sino provocado por la ruptura súbita del vínculo que nos une a nuestro elegido. El dolor de amar es pues un dolor traumático (Nassio, 2007: 32)

El dolor psíquico como reacción de defensa frente al trauma "una aspiración en la psique produce un efecto de succión en la cantidad de excitaciones vecinas [...] ese proceso de aspiración tiene los efectos de una herida" (Nassio, 2007: 36)

El yo concentrado en sostener la imagen inflada de lo perdido cumple con las condiciones donde "el dolor expresa la turbulencia de las pulsiones en el campo del ello" (Nassio, 2007: 46) y aflora en la dimensión del sufrimiento tanto por la sobreinvestidura del recuerdo como por la ausencia.

Por lo cual el fenómeno del amontonamiento estaría en una condición anterior al proceso de duelo, no permite su entrada ni un trabajo, coagula la libido y la detiene en un no-movimiento donde el padecer aparece puesto en otro lugar que no es del montón.

A decir de Martínez (2013) La dinámica de los momentos de alienación entre sujeto y Otro como en el caso de la demanda siempre existirá, al igual que las secuencias de separación, pero en esta última las condiciones se pueden establecer un tanto complicadas: "toda separación implica un corte y una pérdida: es el precio a pagar" (Martínez. 2013:65) se da el objeto como la posibilidad de una distancia con el Otro, y al producir se pierde, una apuesta que siempre pierde y es condición que se dé. Por lo tanto "en la medida en que un duelo nos mantiene unidos, no al Otro, sino a eso que él representa, es decir a nuestra falta, es que resulta un proceso de no-corte" (Martínez. 2013:65)

La dinámica del amontonamiento respondería al proceso donde no es posible la pérdida, pero incluye su ausencia con un valor de posibilidad en tanto se mantiene en reserva y reposo para ser 
usado. En consecuencia, como lo mani- y no responsabilizarse de su dolor, este fiesta Alice Miller (¿año?), para no perder se transfiere como forma de tramitación.

\section{CONCLUSIONES}

En nuestro recorrido, hemos definido la condición del objeto, en tanto ausencia, en el orden de la alucinación dando paso a la condición de un separar dada en el trabajo del duelo. Al plantearnos el amontonamiento como una modalidad de no pérdida lo proponemos como una forma de no responsabilizarse por el proceso del duelo.

Así se evita la penosa tarea de dar cabida al dolor psíquico, y de la responsabilidad que recae en un "hacerse cargo" de sus producciones.

La adición acompañada de la intolerancia a la ambigüedad establece en el amontonamiento una manifestación de la ruptura del vínculo con el Otro, lo ignora.
Esto nos lleva a proponer que la condición del amontonamiento se muestra en una linealidad sin afecto, es un lugar de no-acción donde se muestra lo real.

Estos planteamientos no evitan el sufrimiento, lo delegan a un subrogado establecido en la condición de un semejante ya sea bajo la figura del enemigo o bajo la figura del marginado.

La humanidad siempre ha tenido que vérselas con lo real en tanto le impone una insistencia de trabajo a la psique, sin embargo, en cada época, en cada cultura, los intentos fracasados de tolerar y de-velar se dan en el nivel de lo cotidiano. 


\section{BIBLIOGRAFÎA}

BION, Wilfred (1977). Volviendo a pensar. Buenos Aires: Paidós.

BRODSKY, Graciela (2012). Los envoltorios de la extimidad. En Nueva Escuela de Psicoanálisis (NEL) - Bogotá: Descargado de http://nelbogota. blogspot.com/2012/08/los-envoltorios-de-la-extimidad.html.

FREUD, Sigmund (1950). El proyecto de psicología. Obras completas. Tomo I. Buenos Aires: Amorrortu Editores.

FREUD, Sigmund (1900). La interpretación de los sueños. Obras completas. Tomo IV - V. Buenos Aires: Amorrortu Editores.

FREUD, Sigmund (1901). Psicopatología de la vida cotidiana. Obras completas. Tomo VI. Buenos Aires: Amorrortu Editores.

FREUD, Sigmund (1905). Tres ensayos de teoría sexual. Obras completas. Tomo VII. Buenos Aires: Amorrortu Editores.

FREUD, Sigmund (1914). Recordar, repetir, reelaborar. Obras completas. Tomo XII. Buenos Aires: Amorrortu Editores.

FREUD, Sigmund (1917). Duelo y melancolía. Obras completas. Tomo XIV. Buenos Aires: Amorrortu Editores. FREUD, Sigmund (1926). Inhibición, síntoma y angustia. Obras comple- tas. Tomo XX. Buenos Aires: Amorrortu Editores.

FREUD, Sigmund (1930). El malestar en la cultura. Obras completas. Tomo XXI. Buenos Aires: Amorrortu Editores.

KRISTEVA, Julia (2013). Poderes de la perversión. México. Siglo XXI Editores.

LACAN, Jacques (1956-1957). El seminario. Libro IV. La relación de objeto. Buenos Aires: Paidós.

LACAN, Jacques (1964). El seminario. Libro XI. Los cuatro conceptos fundamentales del psicoanálisis. Buenos Aires: Paidós.

MARTINEZ, Horacio (2013). "Lo que hay que perder". En Psicoanálisis y el hospital: Historización y duelo. Año 22. Número 43. Buenos Aires.

MENASSA, Miguel, DIEZ, Amelia (1996). Deseo de nada -fobia y fetiche-. Madrid: Editorial grupo cero.

MILLER, Alice.(2005). El cuerpo nunca miente. Buenos Aires: Tusquets Editores.

MILLER, Jacques-Alain (2010). Extimidad. Los cursos psicoanalíticos. Buenos Aires: Paidós.

NASSIO Juan David. (2007). El dolor de amar. Barcelona: Editorial Gedisa.

Real Academia Española. Diccionario de la Real Academia de la Lengua Española. http://dle.rae.es/?id=2PEwGhj) 
